\title{
OPTIMAL STRIDE LENGTH CONSIDERATIONS FOR MALE AND FEMALE RECREATIONAL RUNNERS
}

\author{
B. C. ELLIOTT, DipPhysEd, MEd, PhD and B. A. BLANKSBY, DipPhysEd, MEd, PhD \\ Department of Physical Education and Recreation, University of Western Australia, Nedlands
}

\section{INTRODUCTION}

Running is a widely-used human movement pattern. In terms of evolution, running has developed primarily for endurance because speed was not a major factor in determining the biological success of humans. Forty thousand years ago this endurance-oriented "jog-trot" action was used for hunting and gathering and, since that time, no major anatomical changes have occurred in the running apparatus.

Today, the need to run for either speed or endurance is confined mainly to artificially designed athletic contests or perhaps to catch a train or bus.

Jogging is experiencing popularity also because of its physiological benefits. However, if guidelines for optimal performance are unavailable or ignored, then unused overweight bodies may place undue strain on the musculo-skeletal system through inappropriate application of forces during the jogging cycle.

Features of animals having running ability greater than humans frequently include digitigrade gaits, with long and light limbs. The muscle bellies are nearer to the mass centre and the distal segments more tendinous. Human sprinters attempt elongation of the limbs by running on the ball of the foot but the muscular strain involved makes it impractical to do so for any distance longer than a sprint. Increased cushioning by the wellsprung human foot is made by rolling from the heel as the distances to be run become longer. The large forces generated at heel-strike due to deceleration and acceleration about the centre of gravity with each step are influenced by the anthropometric dimensions of the lower limb of the jogger. The adoption of optimal rate and length of stride in an attempt to tailor these factors to individual anthropometric measures may be crucial in increasing jogging efficiency.

The present study sought to examine the freely chosen stride-length (henceforth $S L$ ) and stride-rate (henceforth SR) changes while running on a treadmill at 4 graded velocities.

\section{Related Literature}

Hoffman (1965) and Hoffman (1967, cited in Hay 1973) investigated the anthropometric dimensions of both female and male sprinters in relation to their SL and SR. She conciuded that females sprinted with an SL equal to 1.15 times the height and 2.16 times the lower limb length (trochanterion) of the athlete. Males were similar, recording SL of 1.14 times height and 2.11 times their trochanterion. Another study by Rompotti (1967, cited in Hay, 1973) concluded that the normal full-speed running SL was $1.17 \times$ height \pm 4 inches.

A close inverse relationship was also found between height, lower limb length and SR, while longer anthropometric segments resulted in decreased SR (Hoffman, 1965). A further study by Hogberg (1952a) found SL to be dependent upon lower limb length up to velocities of $7.5 \mathrm{~m} / \mathrm{s}$. Beyond this speed SR played a more dominant role except that subjects shorter in stature continued to increase SL despite a limb length of $4 \mathrm{~cm}$ less than a taller group. It was concluded that at higher speeds the power of the leg drive and not the lower limb length was of greater importance for the choice of SL.

In view of Hoffman's (1965) results, further analysis is required to resolve the apparently conflicting viewpoints.

When élite female and male sprinters of similar body height, length of lower limb and stride were compared, the females were slower over $100 \mathrm{~m}$ because of markedly lower SR (Hay, 1973).

A comparison of good and élite distance runners resulted in a correlation between $S L$ and lower limb length of 0.67 for the élite group and -0.10 for the good runners when running at $4.97 \mathrm{~m} / \mathrm{s}$ (Cavanagh et al, 1977). Regardless of lower limb length, the good runners tended towards longer strides while the élite group used strides better related to their lower limb lengths.

\section{METHODS}

Ten male and ten female physical-education students at the University of Western Australia acted as subjects. All were regular joggers, experienced treadmill runners, skilled athletes, but not competitive runners.

Anthropometric measurements of height and lower limb length were recorded (Montagu, 1960).

Treadmill speeds began at $2.5 \mathrm{~m} / \mathrm{s}$, which is considered to be approximately that velocity at which men break into a run from walking (Alexander, 1977). Further increments were made such that the subjects also ran at $3.5 \mathrm{~m} / \mathrm{s}, 4.5 \mathrm{~m} / \mathrm{s}$ and $5.5 \mathrm{~m} / \mathrm{s}$. 
A Photosonics $16 \mathrm{~mm}$ movie camera, loaded with 200 ASA Kodak Tri-X reversal film and operating at one hundred fps., was used in all filming procedures. The camera was secured on a tripod and positioned so that the focal axis of the lens ( $25 \mathrm{~mm}$ Schneider) was perpendicular to the plane of motion and $10 \mathrm{~m}$ from the treadmill. Placement of the camera at this distance from the subject provided an image of the runner that was large enough to ensure accurate identification of anatomical features and also negated both angular and linear distortion (Atwater, 1973).

Although motor driven cameras operate fairly accurately, deviations from the selected filming speed are possible (Knuttgen, 1961). Therefore, a large sweephand clock, subdivided into $0.02 \mathrm{~s}$ intervals, was included in the field of vision to check camera speed. In order to allow the desired film speed to be reached, the camera was operated for $2 \mathrm{~s}$ before any subject was filmed. After processing, the film was projected by a Specto Motion Analyser onto a screen such that as large an image as possible was provided for evaluation. Stride length was calculated by adding together the period of support and non-support, and multiplying this figure by the speed of the treadmill belt. The mean of four consecutive strides was determined for each individual from film of both overground and then treadmill running.

Stride rate was defined as the reciprocal of the sum of support and non-support phases averaged over four consecutive strides.

\section{RESULTS AND DISCUSSION}

Means and standard deviations for Height, Trochanterion, SL, SR and ratios for SL:height, SL:trochanterion were calculated (see Tables I-IV). Spearman rho correlations were computed for SL with both height and trochanterion (see Tables $\mathrm{V}$ and $\mathrm{VI}$ ).

Previous studies have recorded $S L$ and $S R$ as the constituents of the running action but, except for sprinting (Hoffman, 1965; Rompotti, 1967, cited in Hay, 1973), little reference has been made to changes occurring in SL and SR as velocity is increased by regular increments. Inspection of Table IV indicates that a linear change in SL and SR occurred as the velocity of running was increased from $2.5 \mathrm{~m} / \mathrm{s}$ to $5.5 \mathrm{~m} / \mathrm{s}$ for both males and females.

The male group in the present study revealed homogeneous height and trochanterion measures when compared with the females (see Table I). This could, in part, reflect the lower correlation levels for males at each selected speed (see Tables V and VI), although a comparison of anthropometric measures and SL indicate a highly consistent relationship (see Table II and III).
TABLE I

Mean Height and Trochanterion Lengths (cm)

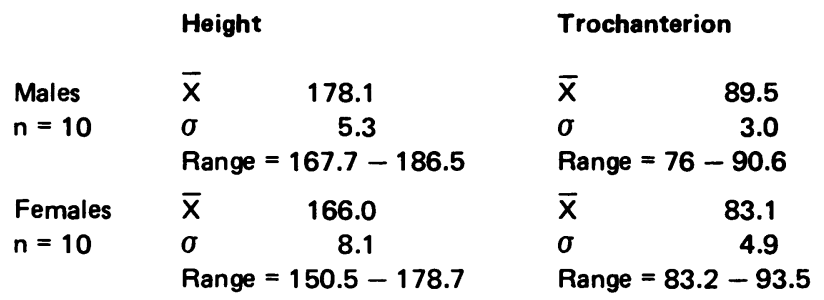

TABLE II

Stride Length : Height

$\begin{array}{lllll}\text { Vel. } & 2.5 \mathrm{~m} / \mathrm{s} & 3.5 \mathrm{~m} / \mathrm{s} & 4.5 \mathrm{~m} / \mathrm{s} & 5.5 \mathrm{~m} / \mathrm{s} \\ \text { Males } & \bar{x} 0.54 & 0.72 & 0.87 & 1.00 \\ n=10 & \sigma 0.03 & 0.06 & 0.03 & 0.05 \\ & & & & \\ \text { Females } & \bar{X} 0.55 & 0.75 & 0.86 & 0.96 \\ n=10 & \sigma 0.05 & 0.06 & 0.05 & 0.05\end{array}$

TABLE III

Stride Length : Trochanterion

$\begin{array}{lllll}\text { Vel. } & 2.5 \mathrm{~m} / \mathrm{s} & 3.5 \mathrm{~m} / \mathrm{s} & 4.5 \mathrm{~m} / \mathrm{s} & 5.5 \mathrm{~m} / \mathrm{s} \\ \text { Males } & \bar{X} 1.10 & 1.46 & 1.71 & 1.96 \\ n=10 & \sigma 0.09 & 0.09 & 0.07 & 0.08 \\ & & & & \\ \text { Females } & \bar{X} 1.11 & 1.48 & 1.70 & 1.89 \\ n=10 & \sigma 0.10 & 0.13 & 0.14 & 0.16\end{array}$

TABLE IV

Stride Length $(\mathrm{m})$ and Stride Rate (per s.) at the Different Velocities

\begin{tabular}{|c|c|c|c|c|c|}
\hline & Velocity & $2.5 \mathrm{~m} / \mathrm{s}$ & $3.5 \mathrm{~m} / \mathrm{s}$ & $4.5 \mathrm{~m} / \mathrm{s}$ & $5.5 \mathrm{~m} / \mathrm{s}$ \\
\hline & Male & $\bar{x} 0.97$ & 1.30 & 1.56 & 1.79 \\
\hline \multirow{4}{*}{$\begin{array}{l}\text { STRIDE } \\
\text { LENGTH }\end{array}$} & $n=10$ & $\sigma 0.03$ & 0.08 & 0.06 & 0.10 \\
\hline & Female & $\bar{x} 0.93$ & 1.22 & 1.44 & 1.60 \\
\hline & $n=10$ & $\sigma 0.07$ & 0.10 & 0.10 & 0.08 \\
\hline & Male & $\bar{x} 2.59$ & 2.71 & 2.90 & 3.08 \\
\hline STRIDE & $n=10$ & $\sigma 0.08$ & 0.17 & 0.12 & 0.17 \\
\hline \multirow[t]{2}{*}{ (per second) } & Female & $\bar{x} 2.68$ & 2.88 & 3.14 & 3.45 \\
\hline & $n=10$ & $\sigma 0.21$ & 0.22 & 0.10 & 0.16 \\
\hline
\end{tabular}


TABLE V

Correlation (Rho) between Stride Length and Height

$\begin{array}{lllll}\text { Vel. } & 2.5 \mathrm{~m} / \mathrm{s} & 3.5 \mathrm{~m} / \mathrm{s} & 4.5 \mathrm{~m} / \mathrm{s} & 5.5 \mathrm{~m} / \mathrm{s} \\ \begin{array}{l}\text { Males } \\ n=10\end{array} & 0.40 & 0.42 & 0.64^{*} & 0.67^{*} \\ \begin{array}{l}\text { Females } \\ n=10\end{array} & 0.65^{*} & 0.67^{*} & 0.70^{*} & 0.70^{*} \\ \text { ("denotes p }<0.05) & & & \end{array}$

TABLE VI

Correlation between Stride Length and Trochanterion

$\begin{array}{lllll}\text { Vel. } & 2.5 \mathrm{~m} / \mathrm{s} & 3.5 \mathrm{~m} / \mathrm{s} & 4.5 \mathrm{~m} / \mathrm{s} & 5.5 \mathrm{~m} / \mathrm{s} \\ \begin{array}{l}\text { Males } \\ \mathrm{n}=10\end{array} & 0.53 & 0.69^{*} & 0.68^{*} & 0.70^{*} \\ \begin{array}{l}\text { Females } \\ \mathrm{n}=10\end{array} & 0.69^{*} & 0.67^{*} & 0.70^{*} & 0.74^{*} \\ \text { (denotes p }<0.05 \text { ) } & & & \end{array}$

Anthropometric comparisons of the male and female joggers were similar to those reported by Nelson (1978) for male and female competitive runners. The height and lower limb length of the female subjects was $93.1 \%$ of their male counterparts, while the ratio of lower limb length to height is $100 \%$ when comparing the two sexes.

Data in Tables II and III demonstrate similar relation. ships between SL:height and SL:trochanterion for both female and male subjects, and suggests that segmental lengths ought to be considered when adopting an optimal jogging technique.

When Hoffman (1965) examined SL:height for sprinters, a correlation of 0.69 resulted. When he isolated the best 15 , the correlation was raised to 0.82 . Similarly, SR:height for the total group resulted in a correlation of 0.49 , and for the best $15,0.81$. At the submaximal speeds used in the present study, a correlation range of 0.65 at $2.5 \mathrm{~m} / \mathrm{s}$ to 0.70 at $5.5 \mathrm{~m} / \mathrm{s}$ resulted. This was a significant relationship between SL and height for females at all four speeds, while correlations of 0.64 at $4.5 \mathrm{~m} / \mathrm{s}$ and 0.67 at $5.5 \mathrm{~m} / \mathrm{s}$, also demonstrated a significant relationship for the male joggers (see Table V). Significant correlations were also found for females at all speeds and males at $3.5,4.5$ and $5.5 \mathrm{~m} / \mathrm{s}$, when SL and trochanterion were compared (Table VI).
Although the best relationship between SL and height, and $S L$ and trochanterion were recorded at the highest speed, the range of correlations was quite homogeneous, especially for the female group.

A longitudinal study by Nelson and Gregor (1976) indicated that college distance runners tended to shorten $S L$ during a 4-year period when their performance improved. They concluded that it was better to understride than overstride. Cavanagh et al (1977) found good distance runners to take SL longer than their élite counterparts. This was in agreement with data from Knuttgen (1961) and Hogberg (1952b), who reported oxygen usage to be twice as high at an SL above the optimum value than at an SL below this value. When comparing male and female runners, Nelson (1978) reported an SL:height ratio of $98 \%$ at $80 \%$ of maximum running speed. In the present study the mean for the female SL:height ratio was $96.1 \%$ when compared with that of the males at $\mathbf{5 . 5}$ $\mathrm{m} / \mathrm{s}$.

At the lower end of the scale, during walking, the loading of body components and the amount of muscular effort required, correspond to the body weight and $S L$ of the individual (Paul, 1970). When running, the support limb absorbs up to 6 times the body weight at each heel strike (Morrison, 1970). Thus a badly selected $S L$ would require even greater muscular effort than that used for walking. At heel strike the greater the horizontal distance that the support foot is placed on the ground ahead of the centre of gravity, the greater the potential retarding effect upon the runner. Atwater (1973) noted that the centre of gravity was positioned more nearly over the foot at heel strike by accomplished runners than was the case for those less accomplished.

In view of the above factors, the increased possibility of injury due to unnecessary joint overloading and mechanically inefficient acceleration/deceleration phases during each stride cycle, one should have regard for the relationship between SL, SR and lower limb lengths when jogging for recreation.

Tables II and III indicate mean SL values as a percentage of height and trochanterion respectively for various speeds and the recreational jogger could be advised to consider these lengths when exercising. This is particularly so when jogging in a group because one frequently adopts a rhythm (SR) of one person in the group, who could be taller or shorter and therefore require a different SL. An awareness of the problems with over-striding could make for a more efficient technique and prevent an unnecessary injury which could limit one's jogging pursuits.

\section{REFERENCES}

Alexander, R. McN. 1977. "Mechanics and Scaling of Terrestrial Locomotion" from Scale Effects in Animal Locomotion, edited by T. J. Pedley, Academic Press, London. 
Atwater, A. E., 1973. "Cinematographic Analyses of Human Movement," Exercise and Sport Reviews 1, edited by J. H. Wilmore: 217-253.

Cavanagh, P. R., Pollock, M. L. and Landa, J., 1977. "A Biomechanical Comparison of Elite and Good Distance Runners", Annals of New York Academy of Sciences, 301: 328-345.

Hay, J. G., 1973. "The Biomechanics of Sports Techniques", Prentice Hall Ltd., Sydney.

Hoffman, K., 1965. "The Relationship Between the Length and Frequency of Stride, Stature and Leg Length", Sport (Belgian), VIII, No. 3 July. (From Track Technique, 46, Dec. 1971: 1463-1469).

Högberg, P., 1952a. "Length of Stride, Stride Frequency, Flight Period and Maximum Distance Between the Feet During Running with Different Speeds", Arbeits Physiologie, 14: 431-436.

Högberg, P., 1952b. "How do Stride Length and Stride Frequency Influence the Energy Output During Running", Arbeits Physiologie, 14: 437-447.

Knuttgen, H. G., 1961. "Oxygen Uptake and Pulse Rate while Running with Undetermined and Determined Stride Lengths at Different Speeds", Acta Physiologica Scandinavica, 52: 366-371.

Montagu, M. F. A., 1960. "A Handbook of Anthropometry, C. T. Thomas".

Morrison, J. B., 1970. "The Mechanics of Muscle Function in Locomotion", Journal of Biomechanics 3: 431-451.

Nelson, R. C. and Gregor, R. J., 1976. "Biomechanics of Distance Running: A Longitudinal Study". Research Quarterly, 47, No. 3: 417-428.

Nelson, R., 1978. "Comparison of Male and Female Athletes", Track Technique, 71, March: 2265-2268.

Paul, J. P., 1970. "The Effect of Walking Speed on the Force Actions Transmitted at the Hip and Knee Joints", Proceedings of the Royal Society of Medicine, 63: 200-202. 